\title{
Development of microprocessor control system of robotic platform for weed vegetation control
}

\author{
A.I. Dyshekov*, M.A. Mirzaev, and I.G. Smirnov \\ Federal State Budgetary Scientific Institution "Federal Scientific Agricultural Engineering Center \\ VIM", 1st Institutsky proezd 5, Moscow, Russia
}

\begin{abstract}
This paper has studied the use of electronic components for automation of robotic complex of weed vegetation control. The components are selected and the interconnection scheme between them is developed for the correct operation of the system in field conditions. This selection was realized because it combines simplicity and efficiency and is a promising and actively developing industry of robotics. At present there are few foreign analogues offering ready-made solutions for automatic control of robotic systems for weed control.
\end{abstract}

\section{Introduction}

A potential solution for reducing herbicide use while maintaining weed control is the sharing use of chemical and mechanical weeding in which the growth of weed vegetation is controlled [11]. Accurate detection of the latter is a necessary condition for the implementation of such strategy as weed control because the applied technique in most farms practically has no electronic automation systems and the actuators are made in the form of standard kinematic transmissions and drives.

Research projects have been analysed to select autonomous vehicles used to investigate weed control techniques. As a result, it was found that all vehicles were equipped with weed detection algorithms. The concepts included four-wheel controls, the main problem of such robots is the complexity of the system and their high cost [12].

The purpose of this study was to develop a microprocessor control system for an autonomous robotic weed control platform (Fig. 1).

The technical task of the microprocessor control system is to automate the process of control of weed vegetation taking into account the reduction of negative impact of herbicides on the environment and increase the accuracy of positioning of the working body [5]. The principal scheme of the microprocessor system consists of a microcomputer, a camera, a step motor controller, step motors, three end sensors, weed vegetation removal system which includes a mechanical nozzle to the system of injection of herbicides brought to it [6] (Fig. 2).

\footnotetext{
* Corresponding author: a.i.dyshekov@gmail.com
} 


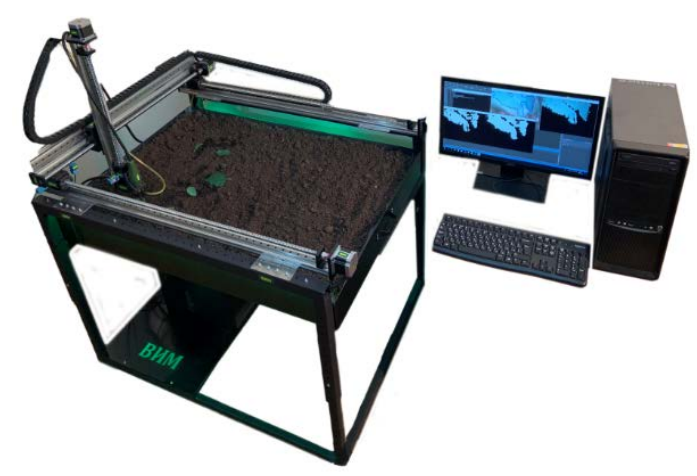

Fig. 1. Laboratory setting for testing microprocessor system for control of weed vegetation.

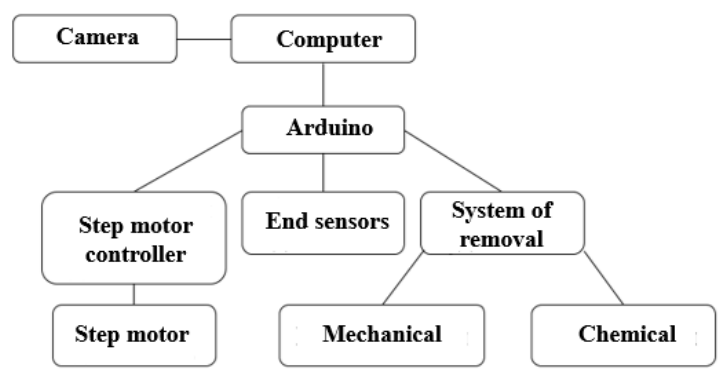

Fig. 2. Generalized structural diagram of the system.

\section{Choose of component base}

Arduino Mega 2560 microcontrollers are used as a calculator (Fig. 3). This calculator allows you to control stepper motors with the lowest load as well as to process the flow of turn on the individual blocks [1].

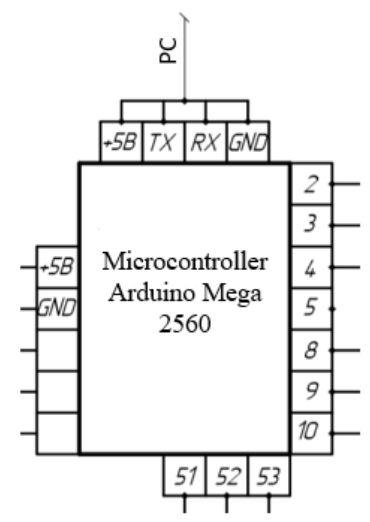

Fig. 3. Schematic designation of the microcontroller ATmega2560. 
To rotate the drive shafts of the carriage on the guideways, a torque of $2.3 \mathrm{~N} \cdot \mathrm{m}$ is required, the NEMA17 stepper motors (Fig. 4) with a maximum torque of $5 \mathrm{~N} \cdot \mathrm{m}$ can cope with this task. The maximum current per phase for this type of motor is $2.8 \mathrm{~A}$ maximum. Based on these parameters it was decided to use the SMSD-1.5 driver (Fig. 5). Block SMSD-1.5 can set the direction, speed, acceleration as well as work on complex algorithms that correspond to the work of the robotic platform in the field [2].

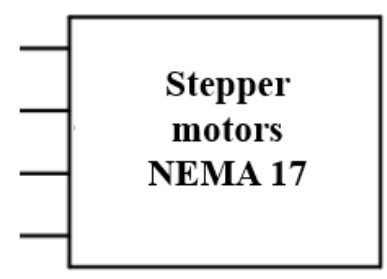

Fig. 4. Schematic designation of stepper motors NEMA-17.

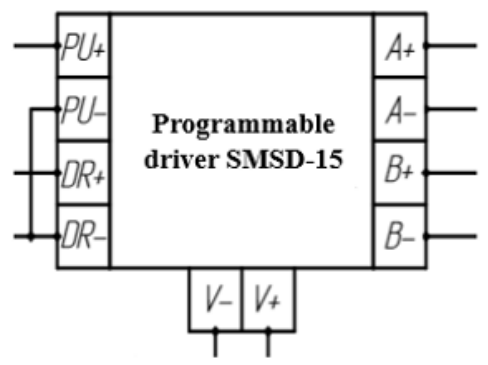

Fig. 5. Schematic designation of stepper motor driver.

This driver is operating in controller mode, receiving commands from from the microcontroller ATmega2560 [1].

To obtain information about the distance traveled by the platform, active inductive noncontact sensors SN04-N DC10-30V were installed on all axes (Fig.6). The platform is read out after calibration and start from the starting point [3].

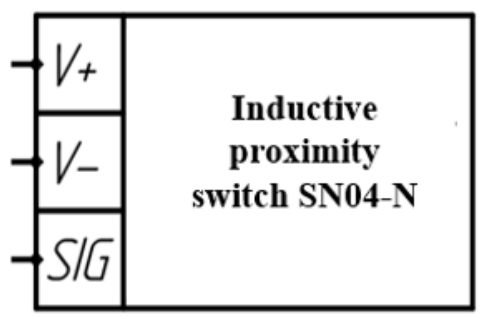

Fig. 6. Schematic designation of the active inductive proximity switch SN04-N.

The center of the installation is the controller that receives the signals from the sensors during calibration and sends the command to start the process to the computer. On the basis of the commands are formed control signals of motors and the working body with the electric motor through the power key N-Channel (Fig. 7 which controls load of DC current: motor 
and pump. When using PWM signal will allow you to smoothly switch the voltage supplied for example to control the speed of the motor [7].

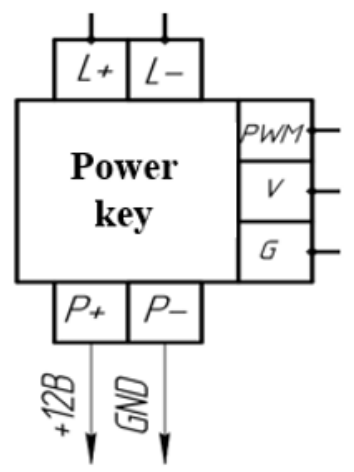

Fig. 7. Schematic designation of the N-Channel power key.

On the basis of the components described above the functional diagram of the automatic control system was developed (Fig. 8).

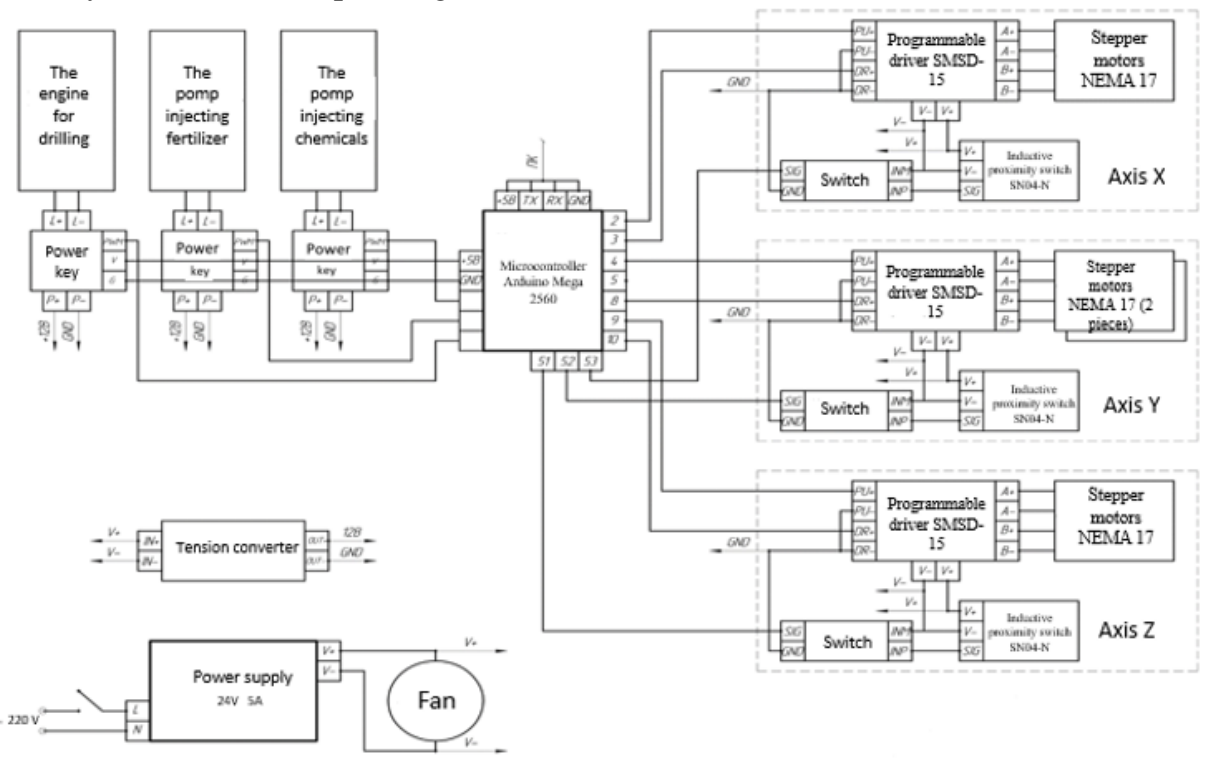

Fig. 8. Functional electrical diagram of automatic control system.

\section{Description of interfaces}

The stepper motor driver used accepts control commands from a laptop computer (PC). The program can be used for moving and positioning the workpiece in the laboratory and field. Due to the prevalence of stepper motor drives the method of synthesis of control algorithms for drives with these motors is considered. The prescribed trajectory is set by code based on the indication of consistently passed control points obtained from the video and photo stream when recognizing the weed vegetation. A microprocessor allows you to control signals from ends for accurate positioning of the carriage, the calculator connects to a PC as a peripheral device, receives and interprets control commands in code. The code defines the coordinates of points in the $\mathrm{X}, \mathrm{Y}$ and $\mathrm{Z}$ axes, then the task of controlling the movement of 
the working body by a given spatial path of motion is solved. Drilling nozzle with point injection is assumed as the working element by default $[8,9,10]$.

\section{Research results}

Research results. All connections are made according to GOST 2.702-2011.

The connection diagram shows all devices and components included in the product, their input and output elements (connectors, board, etc.) [13].

The developed system is divided into two parts: digital and power. The digital part is located in the same case and is protected by a sealed panel (IP56) and includes controller board, driver, power key. An industrial hermetic connector with 12 "mother" pins is built into the housing. The power part is enclosed in a separate box but in the same case. There is a driver for the SHD and a power supply unit in it [4].

\section{Conclusions}

The developed control system of the autonomous robotic complex allows control parameters of weed vegetation by increasing the accuracy of mechanical and chemical influence on the object.

In addition, the system designed for weed removal and spot application of herbicides, has the ability to move in three planes for accurate identification and positioning of the implement and is universal for installation on robotic platforms.

In the course of the analysis the communication interfaces between different devices of the microprocessor system were studied. The requirements to design and installation of electronic systems including the logic part and power supply circuits have been defined.

On the basis of laboratory tests, it can be concluded that a microprocessor system for controlling a robotic weed control complex is applicable in the field.

\section{References}

1. V.B. Brodin, A.V. Kalinin, Systems on microcontrollers and ICs of programmable logic (ECOM, Moscow, 2014) (in Russian)

2. E.V. Burkova, Development of microprocessor technology in formation of information competence of university students (Publishing House of the South Ural Branch of RAO, Chelyabinsk, 2005) (in Russian)

3. V.N. Vasilyev, Y.M. Gusev, Electronic industrial devices (Vicshaya shkola, Moscow, 1988) (in Russian)

4. M. Aitkenhead, I. Dalgetty, C. Mullins, A. McDonald, N. Strachan, Weed and crop discrimination using image analysis and artificial intelligence methods, Computers and electronics in Agriculture, v. 39(3), pp. 157-171 (2003)

5. A.I. Dyshekov, I.G. Smirnov, M.A. Mirzaev, M.A. Shereuzhev, Published Principles of functioning of the autonomous device for weed control for precision agriculture, Published under licence by IOP (2020)

6. A.I. Dyshekov, I.G. Smirnov, M.A. Shereuzhev, Development of algorithm and technical device for weed recognition, Innovazii v selskom hozyaystve, v. (28), pp. 288-294 (in Russian)

7. O.A. Ilyecheva, Complex Systems Logic Modeling and Analysis Technology, Inerniy vestnik Dona, v.4, (2012) (in Russian) Available at: ivdon.ru/ru/magazine/archive/n4p2y2012/1234/ 
8. Y.V. Novikov, Fundamentals of digital circuitry. Basic elements and diagrams. Design methods (Mir, Moscow, 2001) (in Russian)

9. G.I. Pyhaliskiy, Design of microprocessor devices (Politehnika, 2001) (in Russian)

10. Unified Design Documentation System (ESKD). Electrical Flow Rules Available at: docs.cntd.ru/document/1200086241

11. E. Vrindts, J. Baerdemaeker, H. Ramon, Weed detection using canopy reflection, Precis. Agr., v. 3, pp. 63-80 (2002)

12. N. Wang, N. Zhang, J. Wei, Q. Stoll, D.E. Peterson, A real-time embedded weed-detection system for use in wheat fields, Biosyst. Eng., v. 98, 276-285 (2007)

13. Piron, V. Leemans, O. Kleynen, F. Lebeau, M.-F. Destain, Selection of the most efficient wavelength bands for discriminating weeds from crop, Comput. Electron. Agr. v. 62, pp. 141-148 (2008) 